Vogel, D. E., 1967. Petrology of an eclogite- and pyrigarnite-bearing poly-metamorphic rock complex at Cabo Ortegal, NW Spain. Leidse Geologische Mededelingen 40: 121-213.

This synopsis is based on Chapters 1 and 3 of the report 'Weathering and soil formation on mafic and ultramafic rocks in N Galicia, Spain' by G. J. van den Born, $A$. K. Bregt, H. Kok \& J. Zijlstra (editors: P. Buurman \& E. L. Meijer). Research Project J050-816 report 1981, 2nd ed. Dept of Soil Science \& Geology, Agricultural University, Wageningen, 1985. 193 pp., 32 figs., 24 tables, refs., 12 appendices.

Available as paper copy (order R030P, $f 30$ including postage) or on microfiche (order R030M, f 17.50 including postage) at: NARD, c/o Pudoc, P.O. Box 4, 6700 $A A$ Wageningen, Netherlands (telex $45015 \mathrm{blhwg} \mathrm{hl}$.)

\title{
Soil formation on mafic rocks of north Galicia, Spain. 2. Soil micromorphology
}

H. Kok ${ }^{1}$ and P. Buurman (Department of Soil Science and Geology, Agricultural University, P.O. Box 37, 6700 AA Wageningen, Netherlands)

Received 22 January 1985; accepted 14 February 1985

Abstract. Serpentine in soils weathers to undistinguishably small fragments, but in some soils, larger serpentine fragments may be protected by self-supporting iron hydroxide coatings. Unserpentinized minerals accumulate residually. Serpentinite soils have mull humus and locally moder humus, but no amorphous coatings. Characteristics of impeded drainage are few. Pyrigarnite soils have a sandy matrix which is due to the grainy character of the host rock. These soils have moder and amorphous humus, indicating transitions between Inceptisols and Spodosols. Soils on chloritized amphibolite have strong segregation of iron compounds.

Key words: mafic rocks, micromorphology, inceptisols, spodosols, serpentinite.

Introduction. Of the soils described by van den Born \& Buurman (1985), profiles B, $\mathrm{E}$ and $\mathrm{O}$ on serpentinite, profiles $\mathrm{D}$ and $\mathrm{K}$ on chloritized amphibolite, and profile $\mathrm{T}$ on pyrigarnite were sampled for micromorphological investigation. The investigation supports conclusions on rock weathering and soils genesis.

Methods. From each of the profiles, undisturbed samples were collected in steel boxes (sized $15 \mathrm{~cm} \times 8 \mathrm{~cm} \times 5 \mathrm{~cm}$ ). These samples were impregnated with plastic

1 Present address: 1045 NE D-Street 5, Pullmann, WA 99163, U.S.A. 
and thin sections were prepared of size $8 \mathrm{~cm} \times 15 \mathrm{~cm}$. Profiles were not always sampled in full, but care was taken to have samples of each transition between horizons and of fully developed horizons. Thin sections of unweathered rock samples were used for comparison. All thin sections were examined with a polarizing microscope and described. In some cases, minute samples for X-ray diffraction analysis were taken from impregnated samples, to support interpretation.

Results Six crystalline forms of serpentine were recognized in thin section. These forms are similar to the forms S1, S3, S5, S7, S9 and S10 of Rimsaite (1972). Only 'mesh serpentine' (forms S1 and S3) was fairly resistant to weathering. This form has a lattice of white, birefringent serpentine crystals. Irrespective of form, yellowish brown accumulations of iron compounds are formed in cracks upon weathering. Rock fragments fall apart, and S-matrix is formed which contains indistinguishably small serpentine fragments. X-ray diffraction analysis indicates that serpentine is still present in the clay fraction. Sufficiently coherent rock fragments may be enveloped by thick coatings of iron compounds, which become self-supporting. In time, serpentinite within these coatings may dissolve, leaving box-like structures, which may be empty or filled with S-matrix. In some cases, the coating protects the enveloped serpentinite fragment from further weathering, and such fresh serpentinite fragments may be found throughout the profile.

Macroscopically homogeneous serpentinite may contain considerable amounts of unaltered grains of pyroxene, amphibole, chloritized amphibole, chlorite, olivine and magnetite. Such inclusions, if abundant, have a major influence on pedogenic processes, because they constitute a coarse-grained residue after dissolution of the less resistant serpentine. Amphibole and pyroxene grains may occur throughout the profile, either uncoated or with coatings of iron compounds. Olivine grains (forsterite) have a similar distribution but are usually coated. Within coatings, the grains may gradually dissolve. The amount of impurities varies locally.

Chloritized amphibole and chlorite occur as veins in the serpentinite rock, but may be scattered through soil profiles. Chloritized amphibole has amphibolepleiochroitic colours and is found in large agglomerates of laminated packets. Upon weathering, iron hydroxide coatings are formed between laminae, packets fall apart, become grayish brown and loose their pleiochroism. The laminae, finally, weather to unoriented clay particles which loose most of their birefringence.

In serpentinite profiles $B$ and $O$, matrix material constitutes 10 to $40 \%$ and consists of skeleton grains with clay and mull humus. Fabrics are omnisepic, undulic and skelsepic. Profile $\mathrm{B}$ contains many box-like structures; profile $\mathrm{O}$ has some iron segregation due to gleying. Channel vosepic structures, due to pressure, are found in B; some faecal pellets were found in the Bw horizon of this profile. In serpentinite profile $E$, the humus form is moder. The cause of this difference can be either parent rock or microclimate. Profile $\mathrm{E}$ did not have the chemical characteristics of a podzol.

Micromorphology of soils on chloritized amphibolite is quite complex. Humus forms were not recognized in thin section. Matrix constitutes 30 to $50 \%$ of the material, is very inhomogeneous and contains aggregates of fine clay, sometimes in 
recognizable laminated packets. Iron segregation (neoferrans, neoreductans) is prominent along channels and in the matrix and indicates both gley and pseudogley, which reflects changing water regime with season. Fabrics are omnisepic, lattisepic, undulic, and are sometimes inherited from the parent rock. Channel vosepic structures represent pressure rather than illuviation of clay. Clay papules of smectite mineralogy (XRD-analysed) and with a uniform birefringence were found in bands in profile $\mathrm{D}$ and are probably pseudomorphs after chlorite (compare chlorite-smectite transition described by $\mathrm{Zijlstra}$ et al., 1985) and not related to clay transport.

The pyrigarnite rock of profile $T$ consists of plagioclase, quart $z$, amphibole and pyroxene with varying amounts of garnet. The latter may have much larger grains than the other minerals, but is strongly cracked. Profile T has 40-60\% S-matrix consisting of moder humus, skeleton grains and ferric nodules. Aggrotubules are common, indicating intense biological activity. In the $\mathrm{Bhs} / \mathrm{Bw}$ horizons, skeleton grains are partly coated with amorphous humus. Fabrics are isotic and undulic in the Ah horizon, undulic in the Bhs/Bw horizons; skeleton grains are partly coated with amorphous humus. Fabrics are isotic and undulic in the Ah horizon, undulic in the Bhs/Bw horizons. The Bhs horizon did not fulfil the chemical requirements of spodic horizon.

\section{References}

Born, G. J. van den \& P. Buurman, 1985. Soil formation on mafic rocks of north Galicia, Spain. 1. Soil genesis and classification. Netherlands Journal of Agricultural Science 33: 62-64.

Rimsaite, J., 1972. Genesis of chlorite, vermiculite, serpentine, talc and secondary oxides in ultrabasic rocks. Proceedings of the International Clay Conference: 291-302.

Zijlstra, J., E. L., Meijer \& P. Buurman, 1985. Soil formation on mafic rocks of north Galicia, Spain. 3. Chlorite-smectite transformations in weathered chloritized amphibolite. Netherlands Journal of Agricultural Science 33: 67-69.

This synopsis is based on Chapter 5 of the report 'Weathering and soil formation on mafic and ultramafic rocks in N Galicia, Spain' by G. J. van den Born, A. K. Bregt, H. Kok \& J. Zijlstra (editors: P. Buurman \& E. L. Meijer). Research Project J050816 report 1981, 2nd ed. Dept. of Soil Science and Geology, Agricultural University, Wageningen, 1985. 193 pp., 32 figs., 24 tables, refs., 12 appendices.

Available as paper copy (order R030P, $f 30$ including postage) or on microfiche. (order R030M, f 17.50 including postage) at: NARD, clo Pudoc, P.O. Box 4, 6700 AA Wageningen, Netherlands (telex $45015 \mathrm{blhwg} \mathrm{hl}$ ). 